\title{
Stem cell implantation for osteonecrosis of the femoral head
}

\author{
Young Wook Lim ${ }^{1}$, Yong Sik Kim ${ }^{1}$, Jong Wook Lee ${ }^{2}$ and Soon Yong Kwon ${ }^{3}$
}

What is the most effective treatment for the early stages of osteonecrosis of the femoral head? We assessed multiple drilling and stem cell implantation to treat the early stages of osteonecrosis of the femoral head. We report the clinical and radiological results of stem cell implantation and core decompression. In total, 128 patients (190 hips) who had undergone surgery were divided into two groups based on which treatment they had received: (1) multiple drilling and stem cell implantation or (2) core decompression, curettage and a bone graft. The clinical and radiographic results of the two groups were compared. At 5-year follow-up, in the stem cell implantation group, 64.3\% (27/42) of the patients with Stage Ila disease, 56.7\% $(21 / 37)$ of the patients with Stage IIb disease and $42.9 \%(21 / 49)$ of the patients with Stage III disease had undergone no additional surgery. In the conventional core decompression group, 64.3\% (9/14) of the patients with Stage Ila disease, 55.6\% (5/9) of the patients with Stage IIb disease and $37.5 \%(3 / 8)$ of the patients with Stage III disease had undergone no additional surgery. Success rates were higher in patients with Ficat Stage I or II lesions than in those with Stage III lesions. There were no statistically significant differences between the groups in terms of success rate or in the clinical and radiographic results of the two methods. Essentially the same results were found with stem cell implantation as with the conventional method of core decompression.

Experimental \& Molecular Medicine (2013) 45, e61; doi:10.1038/emm.2013.128; published online 15 November 2013

Keywords: core decompression; osteonecrosis; stem cell implantation

\section{INTRODUCTION}

Osteonecrosis of the femoral head $(\mathrm{ONFH})$ is a debilitating disease in orthopedics, frequently progressing to femoral head collapse and osteoarthritis. Early intervention prior to collapse is key to a successful outcome in joint-preserving procedures. Treatment options for early-stage ONFH include electrical stimulation, core decompression, rotational osteotomy and non-vascularized and vascularized bone grafting. ${ }^{1,2}$ Core decompression is the most widely used procedure for treating ONFH; however, its efficacy remains controversial. ${ }^{1,3}$ Vascularized fibular graft has a satisfactory success rate, as high as $90 \%$ in early-stage osteonecrosis, and is superior to core decompression; however, there is still great concern owing to morbidity at the donor site and associated complications. ${ }^{4}$ This concern has prompted continuing investigations into novel methods for the treatment of ONFH.

Bone marrow cells contribute to bone repair after systemic or local implantation in animals and humans. For local bone disease, several experimental approaches in animal models have been used to elicit bone formation in segmental bone defects, including the implantation of bone marrow, ${ }^{5}$ mesenchymal stem cells, ${ }^{6}$ osteoconductive extracellular matrix scaffolds, ${ }^{7,8}$ and bone morphogenetic proteins in various matrices. $^{9,10}$ Recently, mesenchymal stem cells have been used as an adjunct to core decompression to improve clinical success in the treatment of pre-collapse hips. ${ }^{11-14}$ Several studies have shown that the implantation of mesenchymal stem cells can improve Harris hip scores and radiographic findings; clinical results have been closely related to the numbers and concentration of mesenchymal stem cells transplanted. ${ }^{13,14}$

We investigated whether multiple drilling and stem cell implantation in the treatment of ONFH would improve clinical and radiographic results compared with conventional core decompression and bone graft. We also evaluated the effects of the stage of osteonecrosis, lesion size and location

\footnotetext{
${ }^{1}$ Department of Orthopaedic Surgery, Seoul St. Mary's Hospital, College of Medicine, The Catholic University of Korea, Seoul, Korea; ${ }^{2}$ Department of Hematology, Seoul St. Mary's Hospital, College of Medicine, The Catholic University of Korea, Seoul, Korea and ${ }^{3}$ Department of Orthopaedic Surgery, Yeouido St. Mary's Hospital, College of Medicine, The Catholic University of Korea, Seoul, Korea Correspondence: Professor SY Kwon, Department of Orthopaedic Surgery, Yeouido St. Mary's Hospital, College of Medicine, The Catholic University of Korea, 62 Yeouido-dong, Yeongdeungpo-gu, Seoul 150 173, Korea.

E-mail: sykwon@catholic.ac.kr
}

Received 30 June 2013; revised 26 August 2013; accepted 28 August 2013 
and risk factors on the clinical outcome of this procedure using survivorship analysis.

\section{METHODS}

\section{Patients}

Between December 2002 and March 2004, 128 patients (190 hips) who had undergone surgery were divided into two groups based upon which treatment they had received: (1) multiple drilling and stem cell implantation (107 patients, 159 hips) or (2) core decompression, curettage and a bone graft (21 patients, 31 hips). The patients were not enrolled consecutively, but convenient sampling was performed according to the procedures.

The indication for the operation was restricted primarily to modified Ficat Stages ${ }^{15,16}$ I, IIa and IIb, although some patients with Stage III disease (under 45 years old) were included if the size of the lesion was greater than $30 \%$ and if the lesion was located laterally. The operation was not performed on patients older than 60 years. Among the stem cell implantation group, 21 patients (31 hips) were lost to follow-up; therefore, 86 patients (128 hips) were available for study. All data were retrieved retrospectively from our institution's database. No patients were seen or contacted specifically for this study. Institutional review board approval for the study was obtained.

The percentage of hips affected by osteonecrosis in this series of 190 hips was $26.6 \%$ in patients taking corticosteroids, $23.4 \%$ in patients with excessive alcohol intake and $44.5 \%$ in patients with unknown causative factors (Table 1). In 62 patients, the procedure was performed bilaterally under the same anesthesia. Patients were allowed to bear weight using crutches at 2 weeks after surgery, and full weight-bearing was permitted after 6 weeks.

The diagnosis of femoral head osteonecrosis was made using anteroposterior and lateral plain radiographs or magnetic resonance imaging scans. The diagnosis of osteonecrosis on magnetic resonance imaging scans was based on band-like abnormal signals, band-like hypo-intense zones on T1-weighted images and matching hyperintense zones on short tau inversion images.

\section{Operation technique}

Marrow was aspirated from the posterior iliac crests with the patient in the lateral position under general anesthesia. After deep insertion of a beveled needle $(6-8 \mathrm{~cm}$ long and $1.5 \mathrm{~mm}$ in internal diameter) into spongy bone, the marrow was aspirated into a $50-\mathrm{ml}$ plastic syringe. The needle was moved toward the surface through the same insertion site, and successive aspirations were performed, turning the needle $45^{\circ}$ after each aspiration. The marrow was aspirated in small fractions to reduce the degree of dilution by peripheral blood. Using the same skin opening, several perforations were made in the iliac crest. All aspirates were pooled in plastic bags containing cell culture medium and anticoagulant solution (citric acid, sodium citrate and dextrose). The pooled aspirates were then filtered to separate cellular aggregates and fat.

The aspirated material was reduced in volume to increase the stem cell content. This was done by removing some of the red blood cells (non-nucleated cells) and the plasma in such a way as to retain only the nucleated cells: mononuclear stem cells, monocytes and lymphocytes. The marrow was concentrated in a cell separator. A 5-min centrifugation $(400 \times g)$ was used to force the polynuclear cell layer, which was heavier because of the volume of its nuclei, to the periphery, where it was collected and separated from the remainder of the marrow. The leukocyte layer was removed at a flow rate of $100 \mathrm{ml} \mathrm{min}^{-1}$ for $40-50 \mathrm{~s}$. The lighter red cells, without nuclei, were in the center and were recovered with the plasma. All that remained was the mononuclear layer containing the stem cells. This centrifugation method reduced a $150-\mathrm{ml}$ bone marrow aspirate to a concentrated myeloid suspension of approximately $30 \mathrm{ml}$ of stem cells; this suspension was poured into a syringe for reinjection. MNC and $\mathrm{CD}^{+}{ }^{+}$cell counts were performed on each collected bag using a fluorescence-activated cell sorter Aria II (Becton Dickinson, San Jose, CA, USA).

Patients were placed on a fracture table with an image intensifier and a C arm. Decompression was performed using a percutaneous approach with a 3-mm diameter trephine. The bone marrow was injected into the femoral head using a small trocar. The instrument was introduced through the greater trochanter, as in conventional

Table 1 Patient data

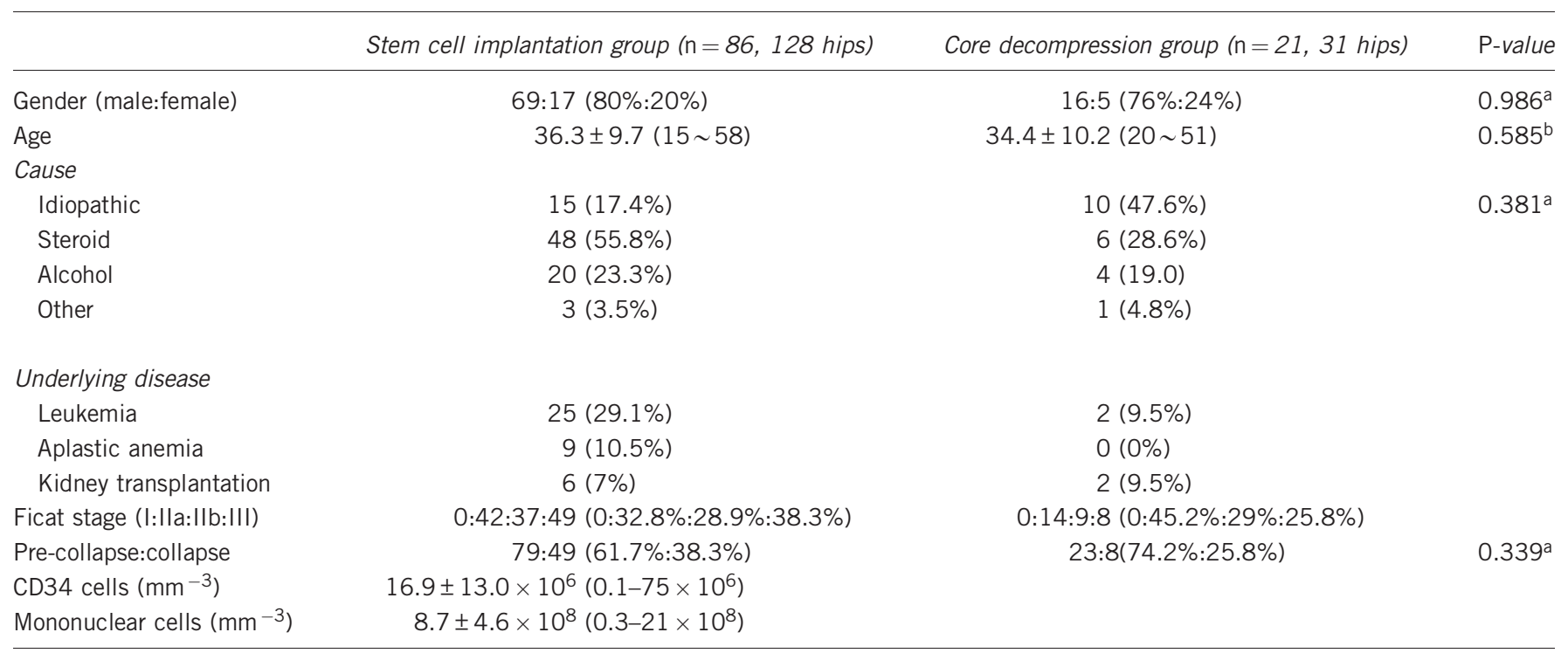

aAnalyzed by chi-squared test.

${ }^{b}$ Analyzed by independent $t$-test. 


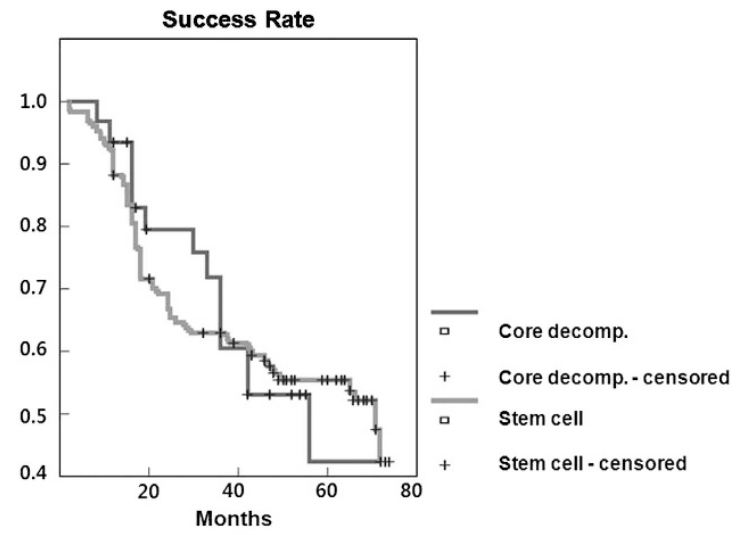

NO. OF PATIENTATRISK

$\begin{array}{llllll}\text { Stem cell } & 128 & 92 & 79 & 73 & 69 \\ \text { Core decomp. } & 31 & 25 & 20 & 17 & 17\end{array}$

Figure 1 Success rates of stem cell implantation and core decompression according to the Kaplan-Meier method. The difference between the groups was statistically insignificant (logrank test, $P<0.8527$ ).

core decompression. Its position in the femoral head and in the necrotic segment was monitored with fluoroscopy. Typically, two or three holes were made. The preoperative magnetic resonance imaging scans and image intensifier views were used together to determine the site of the lesion because, at the time of treatment, the plain radiographs showed little, if any, evidence of necrosis. To prevent leakage of the marrow, fibrin glue was subsequently injected.

Follow-up radiographic and clinical examinations were performed at 6 weeks, 3 months, 6 months, 1 year and then annually thereafter. Preoperative anteroposterior and lateral radiographs were assessed to determine the modified Ficat stages. ${ }^{15,16}$ Follow-up radiographs were used to assess the progression of collapse. ${ }^{17}$ We defined failure as the need for surgery or a Harris hip score below 75 points. ${ }^{18-21} \mathrm{We}$ considered the procedure successful if the patient did not have subsequent hip surgery and if they had a Harris hip score of 75 or greater. Any collapse seen on plain radiographs during follow-up was defined as a radiological failure.

Survivorship analysis was performed using the Kaplan-Meier method, and any additional surgery and a Harris hip score less than 75 points were defined as end points. We used the log-rank test to calculate the statistical significance of differences between KaplanMeier survival curves. Statistical analyses were performed using the SPSS software (ver. 11.5; SPSS, Inc., Chicago, IL, USA).

\section{RESULTS}

We observed no difference ( $P=0.8527$; Figure 1$)$ in the success rate between the stem cell group and the core decompression group: $73 / 128$ hips $(57.0 \%, 95 \%$ confidence interval: $53.88-$ 61.49 ) and $17 / 31$ hips (54.8\%, 95\% confidence interval: $40.32-$ $57.89)$, respectively, in the Kaplan-Meier survivorship curves at the 5-year time point. We observed statistically significant differences (log-rank test, $P=0.0414$; Figure 2) in the success rate between the pre-collapse state (Ficat II) and the collapsed state (Ficat III): 64/102 hips (62.7\%, 95\% confidence interval: 59.45-64.89) and 24/57 hips (42.1\%, 95\% confidence interval: 36.85-47.03), respectively, in the Kaplan-Meier survivorship
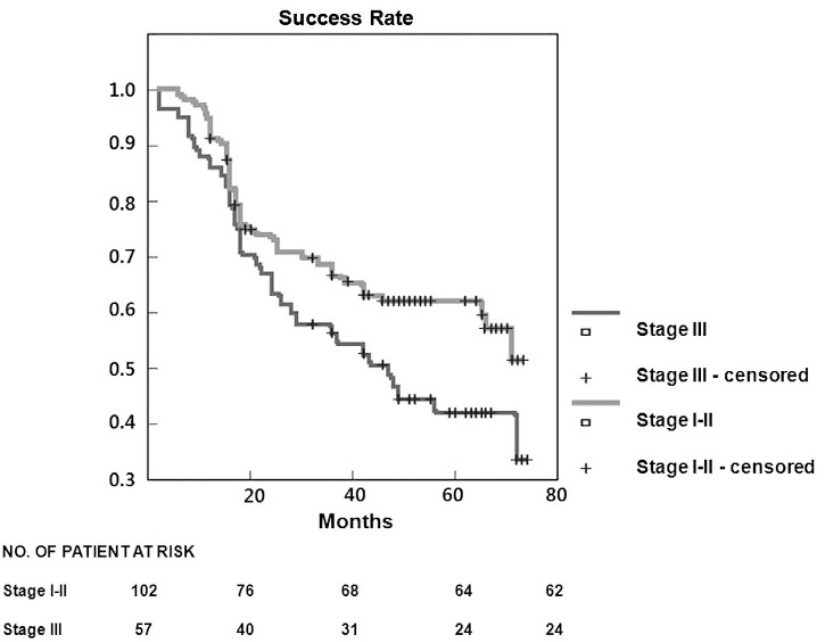

Figure 2 Success rates of preoperative Ficat stage I-II and III according to the Kaplan-Meier method. The difference between the groups was statistically significant (log-rank test, $P=0.0414$ ).

curves at the 5-year time point. The mean follow-up was 87 (range, 8-134) months.

In the stem cell group, 59 hips were considered unsuccessful at the last follow-up. Forty-seven of 59 hips required additional surgery (46 total hip arthroplasties and 1 bipolar arthroplasties), and 12 hips had a Harris hip score below 75 points and showed additional collapse during the follow-up period. In the core decompression group, 14 hips were considered unsuccessful at the last follow-up. Eleven of 14 hips required additional surgery ( 9 total hip arthroplasties and 2 bipolar arthroplasties), and 3 hips had a Harris hip score below 75 points and showed additional collapse during the follow-up period. The mean postoperative time until additional surgery was 32 months (range, 2-96 months) in 58 hips. Most of the failures occurred within 3 years (84\%), and the failure rate decreased rapidly thereafter.

In the stem cell group, the mean injected CD34 + cells were $1.69^{\star} 10^{7}$ cells (range, $0.1 \times 10^{7}-7.5 \times 10^{7}$ ).

\section{DISCUSSION}

Of the various treatment options available to avoid a total hip arthroplasty, core decompression, as described originally by Ficat $^{15}$ and later by Hungerford, ${ }^{2,22}$ is one of the most commonly used surgical treatments for ONFH. Theoretically, core decompression should decompress the diseased area of the femoral head, decrease the intraosseous pressure, improve vascular tissue in-growth and blood flow and prevent additional episodes of infarction. We expected that with the addition of stem cell implantation, all of the therapeutic effects of core decompression could be achieved with better clinical results. A wide range of success rates (29-90\%) has been reported for core decompression. ${ }^{15,23-25}$ According to Mont et al., ${ }^{26} 63.5 \%$ of 1166 hips reviewed between 1960 and 1993 achieved a satisfactory clinical result after core decompression. 
The stage predicted the outcome, with a success rate of $84 \%$ of hips with Stage I disease, $65 \%$ of hips with Stage II disease and $47 \%$ of hips with Stage III disease.

Our study has several limitations. First, the number of subjects in the core decompression group was smaller than in the stem cell group. Second, the proportion of steroid-related cases was larger in this study than in the literature because our institution is well-known for its leukemia center. However, we do not think that stratification is important because numerous studies have shown that there is no difference in the clinical outcomes of various risk groups. ${ }^{14,16,27,28}$ Third, we retrospectively reviewed records from only one hospital, which introduces the possibility of bias by excluding patients who were treated at other hospitals.

We included a large number of patients operated on by a single surgeon. It has been shown that when done properly, the procedure has an extremely low incidence of complications and was effective for treating patients with earlier stages of avascular necrosis compared with patients in previous studies. $^{3,14,20,29}$ Significant differences in outcome were observed in patients who had more cells transplanted, as opposed to patients with fewer progenitor cells in the iliac crest and fewer transplanted cells. This phenomenon may be related to an increased repair capacity in the region of borderline osteonecrosis when progenitor cells are transplanted into the osteonecrosis and the femoral head. Such a phenomenon (repair of osteonecrosis) has been reported previously with systemic allogeneic bone implantation in some patients. ${ }^{30}$

We found that multiple drilling and stem cell implantation produced outcomes comparable to those of other core decompression techniques. Multiple drilling and stem cells implantation did not change the natural course of ONFH. Significant differences in outcome were observed in patients who had more cells transplanted, as opposed to patients with fewer progenitor cells in the iliac crest and fewer transplanted cells.

1 Petrigliano FA, Lieberman JR. Osteonecrosis of the hip: novel approaches to evaluation and treatment. Clin Orthop Relat Res 2007; 465: 53-62.

2 Mont MA, Jones LC, Hungerford DS. Nontraumatic osteonecrosis of the femoral head: ten years later. J Bone Joint Surg Am 2006; 88: $1117-1132$

3 Lieberman JR. Core decompression for osteonecrosis of the hip. Clin Orthop Relat Res 2004; 418: 29-33.

4 Scully SP, Aaron RK, Urbaniak JR. Survival analysis of hips treated with core decompression or vascularized fibular grafting because of avascular necrosis. J Bone Joint Surg Am 1998; 80: 1270-1275.

5 Grundel RE, Chapman MW, Yee T, Moore DC. Autogeneic bone marrow and porous biphasic calcium phosphate ceramic for segmental bone defects in the canine ulna. Clin Orthop Relat Res 1991; 266: 244-258.

6 Bruder SP, Kraus KH, Goldberg VM, Kadiyala S. The effect of implants loaded with autologous mesenchymal stem cells on the healing of canine segmental bone defects. J Bone Joint Surg Am 1998; 80: 985-996.

7 Hollinger JO, Brekke J, Gruskin E, Lee D. Role of bone substitutes. Clin Orthop Relat Res 1996; 324: 55-65.

8 Johnson KD, Frierson KE, Keller TS, Cook C, Scheinberg R, Zerwekh et al. Porous ceramics as bone graft substitutes in long bone defects: a biomechanical, histological, and radiographic analysis. J Orthop Res 1996; 14: 351-369.

9 Cook SD, Baffes GC, Wolfe MW, Sampath TK, Rueger DC, Whitecloud TS The effect of recombinant human osteogenic protein-1 on healing of large segmental bone defects. J Bone Joint Surg Am 1994; 76: 827-838.

10 Gerhart TN, Kirker-Head CA, Kriz MJ, Holtrop ME, Hennig GE, Hipp J et al. Healing segmental femoral defects in sheep using recombinant human bone morphogenetic protein. Clin Orthop Relat Res 1993; 293: 317-326.

11 Gangji V, Toungouz M, Hauzeur J. Stem cell therapy for osteonecrosis of the femoral head. Expert Opin Biol Ther 2005; 5: 437-442.

12 Gangji V, Hauzeur J, Matos C, De Maertelaer V, Toungouz M, Lambermont M. Treatment of osteonecrosis of the femoral head with implantation of autologous bone-marrow cells. A pilot study. J Bone Joint Surg Am 2004; 86: 1153-1160.

13 Hernigou P, Poignard A, Manicom O, Mathieu G, Rouard H. The use of percutaneous autologous bone marrow transplantation in nonunion and avascular necrosis of bone. J Bone Joint Surg Am 2005; 87: 896-902.

14 Hernigou P, Beaujean F. Treatment of osteonecrosis with autologous bone marrow grafting. Clin Orthop Relat Res 2002; 405: 14-23.

15 Ficat RP. Idiopathic bone necrosis of the femoral head. Early diagnosis and treatment. J Bone Joint Surg Br 1985; 67: 3-9.

16 Markel DC, Miskovsky C, Sculco TP, Pellicci PM, Salvati EA. Core decompression for osteonecrosis of the femoral head. Clin Orthop Relat Res 1996; 323: 226-233.

17 Steinberg ME, Hayken GD, Steinberg DR. A quantitative system for staging avascular necrosis. J Bone Joint Surg Br 1995; 77: 34-41.

18 Hasegawa Y, Sakano S, Iwase T, Iwasada S, Torii S, Iwata H. Pedicle bone grafting versus transtrochanteric rotational osteotomy for avascular necrosis of the femoral head. J Bone Joint Surg Br 2003; 85: 191-198.

19 Ito $\mathrm{H}$, Matsuno T, Omizu N, Aoki Y, Minami A. Mid-term prognosis of nontraumatic osteonecrosis of the femoral head. J Bone Joint Surg Br 2003; 85: 796-801.

20 Mont MA, Fairbank AC, Petri M, Hungerford DS. Core decompression for osteonecrosis of the femoral head in systemic lupus erythematosus. Clin Orthop Relat Res 1997; 334: 91-97.

21 Stulberg BN, Davis AW, Bauer TW, Levine M, Easley K. Osteonecrosis of the femoral head. A prospective randomized treatment protocol. Clin Orthop Relat Res 1991; 268: 140-151.

22 Jones LC, Hungerford MW, Khanuja HS, Hungerford DS. Outcome measures for evaluation of treatments for osteonecrosis. Orthop Clin North Am 2009; 40: 179-191.

23 Learmonth ID, Maloon S, Dall G. Core decompression for early atraumatic osteonecrosis of the femoral head. J Bone Joint Surg $\mathrm{Br}$ 1990; 72: 387-390.

24 Meyers $\mathrm{MH}$. Osteonecrosis of the femoral head. Pathogenesis and longterm results of treatment. Clin Orthop Relat Res 1988; 231: 51-61.

25 Saito S, Ohzono K, Ono K. Joint-preserving operations for idiopathic avascular necrosis of the femoral head. Results of core decompression, grafting and osteotomy. J Bone Joint Surg Br 1988; 70: 78-84.

26 Mont MA, Carbone JJ, Fairbank AC. Core decompression versus nonoperative management for osteonecrosis of the hip. Clin Orthop Relat Res 1996; 324: 169-178.

27 Iorio R, Healy WL, Abramowitz AJ, Pfeifer BA. Clinical outcome and survivorship analysis of core decompression for early osteonecrosis of the femoral head. J Arthroplasty 1998; 13: 34-41.

28 Bozic KJ, Zurakowski D, Thornhill TS. Survivorship analysis of hips treated with core decompression for nontraumatic osteonecrosis of the femoral head. J Bone Joint Surg Am 1999; 81: 200-209.

29 Song WS, Yoo JJ, Kim YM, Kim HJ. Results of multiple drilling compared with those of conventional methods of core decompression. Clin Orthop Relat Res 2007; 454: 139-146.

30 Hernigou P, Bernaudin F, Reinert P, Kuentz M, Vernant JP. Bone-marrow transplantation in sickle-cell disease. Effect on osteonecrosis: a case report with a four-year follow-up. J Bone Joint Surg Am 1997; 79: $1726-1730$.

(i) () $€$ This work is licensed under a Creative Commons Attribution-NonCommercial-NoDerivs 3.0 Unported License. To view a copy of this license, visit http:// creativecommons.org/licenses/by-nc-nd/3.0/ 